\section{Bandoleros Y Jinetes Míticos En Iberoamérica}

\section{Resumen}

Asaltos de diligencias, emboscadas, ataques en caseríos, todos sucesos que ocurrían en el pasado con mucha frecuencia, configuran la imagen del bandolero, asaltador de caminos. Pero para comprender bien estas figuras del delito en Iberoamérica hemos de considerar primero la caballería en su generalidad desde tiempo antes de la expansión ibérica en el Continente Americano. Se considera que la capacidad de dominio de muchos imperios de la antigüedad se debió a los animales empleados, especialmente el caballo. Lo mismo sucedió en la conquista americana cuya rapidez se debió en parte al empleo militar de los importados caballos, empleo que poco a poco derivaría hacia el transporte y se generalizaría en todo el Continente americano dando lugar a un tipo de jinete que en su polimorfismo y por su importancia comentaremos en detalle a continuación.

Palabras-Clave: Bandoleros, Jinetes Míticos, Iberoamérica, Expansión, Conquista Americana

\section{Abstract}

Assaults of stagecoaches, ambushes, attacks in hamlets, all events that happened in the past very often, make up the image of the bandit, highway robber. But to understand these figures of crime in Ibero-America we must first consider the cavalry in its generality since a time before the Iberian expansion in the American Continent. It is considered that the ability to dominate many empires of antiquity was due to the animals used, especially the horse. The same happened in the American conquest, whose speed was partly due to the military employment of the imported horses, a job that would gradually lead to transportation and would become widespread throughout the American Continent, giving rise to a type of rider that in its polymorphism and Because of its importance we will comment in detail below.

Keywords: Bandoleros, Mythical Horsemen, Latin America, Expansion, American Conquest
Ángel-B Espina Barrio

Profesor Titular de Antropología Social y Director del Programa de Doctorado de Antropología de Iberoamérica y del Master Universitario en Antropología de Iberoamérica (MAI) de la Universidad de Salamanca. Presidente de la Sociedad Española de Antropología Aplicada.

E-mail:espina@usal.es 


\section{Introduccion}

Asaltos de diligencias, emboscadas, ataques en caseríos..., todos sucesos que ocurrían en el pasado con mucha frecuencia, configuran la imagen del bandolero, asaltador de caminos. Su delictiva acción en grupo (banda) se representa profusamente en cuadros, grabados y láminas, especialmente desde el s. XIX. La ideología romántica propia de tal siglo recrea la figura del bandolero y la idealiza, despojándola en muchos casos de su crueldad, nos ofrece relatos e imágenes que caen en una ingenuidad y un exotismo, a veces poco realista. ¿Es el bandolero un personaje que trabaja a favor del pueblo? ¿Realmente roba a los ricos para dar a los pobres? Quizá no, pero lo que sí parece claro es que el bandolero es un rebelde que compite con los poderes establecidos, muchas veces igual de crueles, para subsistir.

Pero para comprender bien estas figuras del delito en Iberoamérica hemos de considerar primero la caballería en su generalidad desde tiempo antes de la expansión ibérica en el Continente Americano. Se considera que la capacidad de dominio de muchos imperios de la antigüedad se debió a los animales empleados, especialmente el caballo. Tal se afirma del imperio del "Gran Khan" que se extendía desde el Sudeste asiático hasta los límites orientales de Europa y cuyos guerreros montaban los pequeños pero fuertes caballos mongoles. Lo mismo sucedió en la conquista americana cuya rapidez se debió en parte al empleo militar de los importados caballos, empleo que poco a poco derivaría hacia el transporte y se generalizaría en todo el Continente americano dando lugar a un tipo de jinete que en su polimorfismo y por su importancia comentaremos en detalle a continuación. Pero antes de ello observemos que a finales de la Edad Media en Europa se forja la figura y el espíritu de la "caballería", ideal de todo hombre destacado ya sea en la forma de "cruzado", guerrero y, especialmente, como caballero andante. A pesar de que el "Quijote" supone, entre otras cosas, una sátira sagaz a este tipo de ideales, el prestigio de los caballeros permaneció intacto suponiendo en muchos casos un signo de preeminencia social. $Y$ parte de ese espíritu medieval se traspasa a América con los conquistadores que no por casualidad tienen a Santiago ecuestre, entre los castellanos, o a San Jorge para los portugueses, como figuras sacras ecuestres de identificación.

En América muy pronto, asociado a la ganadería especialmente la vacuna, se perfila la figura del llanero, heredero del mayoral hispánico, que va tomando diversos usos, atuendos y costumbres, según el clima y la orografía, pero que conserva muchos rasgos de su origen. Jinetes hábiles y esforzados que proliferan de Norte a Sur en todos los países americanos y que forman parte de su historia y de su leyenda, colaborando a crear identidades nuevas. Tienen diversos nombres, pero su espíritu de libertad, su fuerza viril, su indomabilidad son tan invariantes como el amor hacia su caballo, verdadero complemento de su personalidad y de su vida. Mitificados como "llaneros solitarios", lo fueran o no, representan los pioneros de Arizona, Jalisco, Los llanos del Arauca colombo-venezolano, el Cangaço, la Pampa...Son símbolos icónicos de estas nuevas culturas que amalgaman libertad, individualismo, fuerza, aislamiento del hombre en amplísimas geografías. Son mucho más antiguos y genuinos que el archiconocido "cowboy" que se ha vendido como esencia de lo norteamericano. En realidad, esta es una característica general de casi todos los rasgos que se pretenden genuinamente norteamericanos: suelen ser meros remedos de las altas culturas sureñas. Así la hamburguesa es una torta mexicana o cubana a la que se le sustrae el chile a cambio de suaves pepinillos; la Coca-Cola es una derivación de la zarzaparrilla y hasta el famoso super-mán (o spidermán) es, a poco que pensemos, "el zorro" modernizado. También justiciero, con doble vida, rápido y adorado por las mujeres, aunque, eso sí, su vuelo ya no es en caballo.

Mención aparte merece el jinete charro jalisciense que en sus formas actuales y como representación de lo mexicano es muy reciente, 
no antes de la revolución de 1910, pero que asociado a los capataces del porfiriato y con anterioridad a las haciendas coloniales, tiene sus raíces en los propios caballeros cortesanos. Pocos mexicanos conocen que el término charro y jinete charro se emplean desde mucho tiempo atrás en Salamanca (España), siendo incluso el gentilicio popular de esta provincia. Asimismo, en esta zona eminentemente ibérica también se engalanan con elegantes "charrerías", barrocos adornos de plata o de oro, idénticos a los que hoy vemos en charros y mariachis mexicanos. Pero esto no debe extrañarnos pues los propios salmantinos, a su vez, desconocen que sus queridas charrerías proceden y siguen utilizándose en la cultura bereber de Marruecos. Y este ejemplo, que puede parecer muy particular, es ilustrativo y paradigmático de cómo la cultura hispánica, fuertemente mestiza y mudéjar, es la que pervivirá en América mezclada a su vez con las tradiciones autóctonas.

En Colombia y Venezuela encontramos también a los llaneros desarrollando su subsistencia alrededor de la prolífica ganadería y transformándose en bravos lanceros cuando los avatares de la guerra así lo exigieron, especialmente en las independencias. Una de las primeras descripciones de estos peones llaneros nos la da Humboldt haciendo referencia a "hombres desnudos hasta la cintura y armados con una lanza recorren a caballo las sabanas...". Estos "hombres pardos" unos son libres, o manumisos, y otros esclavos y muchas veces éstos últimos pasarían a ser "cimarrones" huidos a las regiones más inhóspitas del Continente. (Humboldt, 1956)

Por otro lado, José Antonio Páez, famoso caudillo independentista, colabora en sus escritos a conformar las esencias de lo llanero y de sus supuestos peligros: “...los llaneros vivían y morían como hombres a los que no cupo otro destino que luchar contra los elementos y las fieras [...] no son otra cosa los caballos y los toros salvajes. Una lucha incesante en que la vida escapa como de milagro, lucha que pone a prueba las fuerzas corporales, y que necesita una resistencia moral ilimitada...." (Páez, 1946)
Estos llaneros y lanceros míticos ya sean realistas (Boves), o independentistas (Páez) son admirablemente descritos por Arturo Uslar Prieti en sus novelas, especialmente en Las lanzas coloradas (Uslar Prieti, 1993). En la paz el llanero muestra un folclore y unos estilos de vida peculiares pero similares a los descritos y, como en otras ocasiones, con el tiempo se perfilarán estos rasgos como una cultura autóctona; como el "alma llanera" emblemática de toda Venezuela. Por el contrario, en las zonas altas y abruptas norandinas, surge una figura bastante distinta, también mítica para algunas regiones colombianas, como la de Antioquia. Me refiero al arriero, esforzado caminante que, incluso con los pies desnudos, va tirando de las mulas que transportan la valiosa mercancía por veredas imposibles. Sus hazañas, sus posadas, sus zurrones, su atuendo y sus historias están en el inconsciente colectivo de los antioqueños, como lo estuvieron entre los asturianos o leoneses.

Y qué decir de los más modernos, pero no por ello menos arquetípicos cangaçeiros del Nordeste brasileño, que a mitad de camino entre empecinados guerrilleros y bandoleros de Sierra Morena, también como "zorros pernambucanos" "robaban al rico para dárselo a los pobres". Su atrayente figura perdura hasta la actualidad quizá como recuerdo y nostalgia de una rebeldía malograda.

Entre los tipos humanos que existieron en América en simbiosis con sus animales $y$ monturas destaca el gaucho, jinete mestizo que no criollo conocedor de las pampas sureñas. Recibe del indígena no sólo sangre sino técnicas de caza y costumbres. Nos dice Emilio Corbiere hablando de la etimología de la voz "gaucho" que procede del lenguaje indígena, concretamente de "la palabra huaso, fonéticamente guascho, y que servía para distinguir al individuo que se bastaba a sí mismo, carente de padre conocido..." (Corbiere, 1998) Naturalmente que a esta designación hubieron de añadirse características cada vez más positivas, de independencia, arrojo y valentía principalmente, para que llegara a ser 
una de las representaciones más prístinas del "alma argentina".

Pero las primitivas connotaciones del término tocan uno de los aspectos más recóndito y a la vez más significativo del mestizaje iberoamericano. La simbólica pero también, a veces, física "ausencia de padre", que en el plano social se traduce en "ausencia de ley" y en debilidad de las instituciones, y que parece estar en el fondo de muchos conflictos, violencias y desigualdades de la actualidad. Con todo, no es en este importante componente, que mucho tiene que ver con el bandidaje, en el que queremos centrar ahora nuestro análisis si no brevemente en las raíces de estas formas de vida humana asociadas a la ganadería y especialmente a la caballería.

Ya hemos visto que, como en otras zonas de Europa, durante la Edad Media en la Península ibérica se dio el nacimiento del espíritu de la "caballería" y un florecimiento de la ganadería cuyo gremio prevalecía claramente sobre el de los agricultores. Concretamente hablando de diversas zonas de Castilla y León, desde remotas épocas prehistóricas, existe una rica tradición ganadera. Exponente simbólico de la misma son los míticos toros de Guisando, verdaderas petrificaciones de la omnipresencia del vacuno en tales tierras. Para el ganado ovino y el caprino hubo una época floreciente que se inicia como decimos a finales de la Edad Media cuando la Península y la especialmente la zona castellana se vio cruzada de norte a sur por las cañadas de la otrora poderosa Mesta.

Estos caminos pecuarios por los que se realizaba la anual trashumancia, y que hoy en día se quieren de alguna manera recuperar, fueron manzana de discordia entre agricultores y ganaderos. La extensión de las tierras dedicadas a la agricultura creció con el tiempo en la época moderna, muchas veces en detrimento del terreno reservado a las cañadas y al ganado. De hecho, se observa un repliegue de las explotaciones ganaderas hacia la cornisa montañosa que orla la comunidad castellano-leonesa, zona que por su orografía y condiciones ecológicas no sólo favorece el desarrollo de los pastos sino que no resulta tan adecuada para la agricultura. No obstante, para los cerdos, caballos y para el toro de lidia el ecosistema llamado de "dehesa", amplios terrenos con árboles -alcornoques, encinas, etc.- y con espacios intermedios labrados o libres, resultó siempre un hábitat ideal. Allí se desarrollaron los estilos de vida de los jinetes charros, hacendados y capataces, vaqueros o mayorales, antecedentes de todos los considerados en América.

En la figura del jinete tenemos también una incipiente dicotomización de su imagología entre la del caballero, andante o no, pero que se asocia a la defensa del bien, los pobres o de la patria en peligro; y la del jinete malvado, bandido, salteador y asesino. Ciertamente en muchos casos se mezclan las características o se producen evoluciones vitales desde una posición a otra. Pero casi nunca el destacado jinete es estricto defensor de la legalidad y el orden establecido. Asaltantes famosos ya se citan en la época romana y también son muy conocidos los que azotaban en la Edad media el Camino de Santiago. Por otro lado, encontramos la imagen del buen caballero en "El Cid", modelo de guerrero castellano, que sin embargo tendrá liderazgo entre los moros? Por cierto que, para ser caballero, o bandido, da igual que la montura sea un caballo o un camélido, pues las consecuencias y rasgos serán muy similares. En España tenemos como antecedentes de los famosos y románticos bandidos de Sierra morena a los bandoleros monfíes de Sierra Nevada y la Alpujarra. (G. Alcantud, 1999)

Los extremos del simbólico buen caballero van desde el Cid hasta D. Quijote, dos de los iconos más significativos de la historia y la cultura españolas sin olvidarnos del polifacético Santiago. Entre las evoluciones de malos

$Y$ no sólo eso, si no también que su destierro parece que se debió más a aspectos que tenían que ver con la retención de botines de sus correrías que con temas de honor. Así lo señala el Cantar: "El Campeador por las parias fo entrado, grandes averes priso e mucho sobejanos, retovo dellos quanto fo algo; por én vino a aquesto por que fo acusado" (A.A.,Cantar de Mío Cid, 2005, 108). 
jinetes hay que destacar muchas historias de bandoleros que se "echaron al monte" por injusticias previas sufridas y que, sin embargo, guardan algún tipo de moral o de estética en su actividad delictiva. También el caso de partidas de ladrones que tras la invasión napoleónica se convierten en eficaces guerrilleros contra los ejércitos de Francia. Muchos ejemplos podrían citarse de conocidos y famosos guerrilleros: "El charro", Espoz y Mina, etc. Curioso el caso de "El Empecinado", quien fue partisano a favor del rey Fernando VII, el mismo que después le recompensaría y posteriormente le mandaría ejecutar por liberal. Pero la visión clásica del bandolero se fragua en la pluma de escritores románticos y de viajeros, sobre todo franceses, tomando como prototipo el bandolero andaluz de Sierra Morena o de la Sierra de Ronda, según los estereotipos de Mérimée, Gauthier, Lyonnet, etc. Se hacen famosos numerosos casos de jefes de bandas que actúan en toda la Península, pero especialmente en el sur, asaltando diligencias y viajeros y dificultando las ya difíciles comunicaciones de la época con caminos impracticables y ruines posadas con posaderos verdaderamente ladrones. Conocidos son: Tempranillo, Chorrojumo, Escaramillo...

Lo cierto es que su actividad, que ya se daba en el s. XVIII, llegó a sus mayores cotas a principios del s. XIX, y solía ser más sangrienta y cruel que la relatada por los escritores que la idealizaron tras las guerras de la independencia También se dieron casos más urbanos, como el de Luis Candelas en Madrid, bandido quizá de origen peruano. A finales del siglo XIX, con la intervención de la recién creada Guardia Civil, verdadero azote de los forajidos rurales, la actividad de los bandoleros cayó en picado y sólo repuntaría en el siglo XX, con las acciones postguerra civil de tipo político-militar de los llamados "maquis"

Volviendo a América, y concretamente a la cordillera andina, muchos han sido los jinetes y bandoleros que han cruzado sus escarpadas laderas, u obstaculizado sus estrechos pasos, ejerciendo su peculiar oficio. Desde la época del conocido como "demonio de los Andes" (Francisco de Carvajal), hasta el momento actual, como decimos, innumerables son los casos de forajidos, bandidos, insurrectos y guerrilleros que podrían citarse. En Perú y para principios del siglo XX, algunos son recogidos por el juez-etnógrafo y escritor Enrique López de Albújar, en su libro Los caballeros del delito, donde además de una descripción de los que el conoció, nos ofrece unas posibles líneas de interpretación multivariadas sobre el bandolerismo en general, entendido como: "protesta contra la injusticia del poderoso - la extorsión del fuerte; rebeldía contra las rudas determinaciones sociales, hostiles contra el débil y contemporizadoras con el fuerte; desviación de la ética individual por acción de factores biológicos o hereditarios; recurso para satisfacer necesidades reales o ficticias, malas o buenas, creadas por la pasión o el vicio, la miseria o el hambre, pero al fin obra de una fuerza imperiosa y decisiva". (López Albújar, 1936)

Incluso da más posibilidades para explicar el bandolerismo: como sentimiento de libertad o un impulso combativo exaltados; reminiscencia de la vida errante primitiva; resto de la época feudal; e, incluso: "una manifestación de ese comunismo latente que hay en el alma de todo desheredado". (López Albújar, 1936)

Para Colombia ya hemos citado la importancia identitaria de los arrieros, especialmente en Antioquia, pero también existían los que les asaltaban, tradición que se mantiene hasta la actualidad, como bien estudian en su libro: Bandoleros, gamonales y campesinos, Gonzalo Sánchez y Donny Meertens. En esta obra, asimismo, se describen los casos locales de mitad de siglo XX de El "Chispas", "Sangrenegra", Efraín González, "Pedro Brincos", "EL capitán Desquite" ..., y queda patente su ambivalente relación con los gamonales y el campesinado, y que son los antecedentes históricos de las posteriores y actuales guerrillas. En realidad Colombia desde casi siempre ha sufrido en su historia la acción de una especie de "señores de la guerra" medio feudales, y de su contraparte popular, que han vivido del derecho de paso, de la exacción abusiva (hoy llamada "vacuna") si 
no del robo directo. ${ }^{2} \mathrm{Al}$ margen de las ideologías liberal o conservadora se da este tipo de bandidaje, agravado en las últimas décadas por la acción de guerrilleros, paramilitares y narcotraficantes: "pescas milagrosas", cortes de carreteras, robos, secuestros...

Pero quizá una de las figuras míticas que mejor represente a ese jinete legendario que vive al margen de la legalidad y que si no es bandido en sentido estricto es por su característica de ser solitario, de no bandear, es el gaucho sureño del que hemos brevemente hablado. Tiene muchas de las dimensiones que observamos en los jinetes que viven al margen de la ley, pero no por ello ha dejado de ser un referente identitario de las pampas y zonas ganaderas de Suramérica. En principio es un campesino honrado, y diríamos feliz, que por culpa de las arbitrariedades del poder tiene que cambiar su vida normal por una existencia en permanente liminaridad y frontería. Todos los avatares y homicidios posteriores son resultado de ese abuso originario de las autoridades establecidas y una legítima defensa por parte del que, más que explotado u oprimido, diríamos es expoliado de su existencia digna.

$Y$ esto podemos observarlo a poco que leamos una de las versiones más emblemáticas que la literatura ha dado del gaucho, que como es bien sabido es la del Martín Fierro de José Hernández. Es a mediados del siglo XIX cuando se fijan las características de estos jinetes de leyenda, ya sean llaneros, charros o gauchos -o guerrilleros o bandidos de sierra Morena- que, con sus características románticas, pasan a ser las raíces populares de las regionalidades o de las nacionalidades emergentes. $Y$ en ese momento se escriben los versos que cuentan la historia de Martín Fierro, que nos dicen supuestamente con su propia voz:

Tuve en mi pago en un tiempo

hijos, hacienda y mujer,

Esto puede notarse hoy en día por los excesivos impuestos sobre la movilidad, los peajes desorbitados sobre carreteras sin mantenimiento y de paso obligado, incluso, para poder llegar al propio domicilio, etc. pero empecé a padecer Me echaron a la frontera iY qué iba a hallar al volver!: tan sólo hallé la tapera.

(Martín Fierro, 289-294)

Antes de esa penosa vuelta, sufre el gaucho crueles penalidades y abusos, hasta que ya no puede más y se rebela:

\author{
Dende chiquito gané \\ la vida con mi trabajo, \\ y aunque siempre estuve abajo \\ y no sé lo que es subir, \\ también el mucho sufrir \\ suele cansarnos ¡barajo! \\ (Martín Fierro, 973-978)
}

Su paso a la marginalidad es inevitable y obligado, pues su familia y propiedades han sido destruidas y ya nada le anima a sufrir una sumisión tan inútil como insufrible a las normas sociales:
No hallé rastro de rancho; ¡sólo estaba la tapera!
¡Por Cristo, si aquello era
pa enlutar el corazón:
yo juré en esa ocasión
ser más malo que una fiera!
(Martín Fierro, 1009-1014)

A partir de ese momento comienza su vida como prototipo del jinete libre pero asocial, al margen de la ley, y prácticamente solitario en las inmensidades de las pampas. Pasando a ser huido de la justicia, cautivo de indios o fugitivo de todos. Triste, sin duda, pero sin nunca ya someterse, sabe usar su faca, es verdad que sólo cuando no hay otro remedio y en buena lid, y ultimar con destreza a sus mortales enemigos:

\footnotetext{
Y como con la justicia no andaba bien por allí, cuando pataliar lo vi, y el pulpero pegó el grito,
} 


\begin{abstract}
ya para el palenque salí
como haciéndome el chiquito.

Monté y me encomendé a Dios,

rumbiando para otro pago;

que el gaucho que llaman vago

no puede tener querencia,

y ansí de estrago en estrago

vive llorando la ausencia.

Él anda siempre huyendo,

siempre pobre y perseguido;

no tiene cueva ni nido,

como si juera maldito;

porque el ser gaucho... jbarajo!

el ser gaucho es un delito.
\end{abstract}

(Martín Fierro, 1307-1324)

Se fragua su leyenda en el transcurso de sus avatares, que serán cantados por el mismo y por miles de payadores después, creando un figura idealizada que en realidad hubiera sido en otros lugares tenida por la de un simple forajido. Recuérdese, si no, cuando, esta vez ayudado por Cruz, dan muerte a varios policías que venían a prenderle por las muertes del moreno y el de la pulpería:

\footnotetext{
Pero no aguardaron más

y se apiaron en montón;

como a perro cimarrón

me rodiaron entre tantos;

yo me encomendé a los santos

y eché mano a mi facón.

(Martín Fierro, 1537-1542)
}

Lo cierto es que pese a todo Martín Fierro pasa a ser el prototipo de gaucho, el héroe popular, maltratado por la sociedad, pero que no se rinde nunca frente a las adversidades y que tiene una particular ética inquebrantable, aunque no coincida con la legalidad. Es el dueño melancólico de las llanuras:

Sin punto ni rumbo fijo en aquella inmensidá, entre tanta escuridá anda el gaucho como duende;

allí jamás lo sorpriende

dormido la autoridá.

(Martín Fierro, 1433-1338)

En la época actual la presencia de estos legendarios jinetes del bien o del delito ya no es más que simbólica pero bastante extendida, especialmente en el cine o la televisión. Quizá sus prototipos sean más simplistas y desarraigados que en el pasado. Tal es el caso del llanero solitario, el Virginiano, etc. Mención aparte merece el Zorro, jinete hispanomexicano legendario, en los márgenes de la legalidad, que ha protagonizado innumerables relatos y películas. Ya hemos tratado de su parecido estructural con héroes posteriores, como Supremán o Spidermán, etc. Lo cierto es que los bandoleros siguen protagonizando todo tipo de literatura y de expresión artística. En Andalucía encontramos, de la época franquista, un cómic dedicado a la figura de $\mathrm{El}$ Tempranillo, al estilo de los de Roberto Alcázar y Pedrín; y en México abundantes películas sobre charros, mariachis y bandoleros.

En España tuvo hace pocos años una extraordinaria popularidad la serie televisiva dedicada a Curro Jiménez (interpretado por el actor Sancho Gracia) y su banda (el Algarrobo, el Gitano y el Estudiante). Ambientada en Andalucía y en el siglo XIX constó de muchos capítulos.

En Ronda el prestigio del pasado bandolero es tan grande que ha motivado la apertura de un museo temático sobre la cuestión que es muy visitado por los turistas. También jocosamente se emplea un falso atuendo de bandolero para criticar a políticos andaluces tildados de corrupción.

En suma, no cabe duda de que los jinetes liminares y los bandoleros serán siempre unas figuras míticas importantes, tanto de identificación como de expresión artística, de nuestras culturas Iberoamericanas. 


\section{Bibliografía}

A.A., (2005) Cantar del Mio Cid, Espasa, Madrid.

CORBIERE, E.P., (1998) El gaucho. Desde su origen hasta nuestros días, Editorial Renacimiento, Sevilla.

ESPINA BARRIO, A.B. (Dir.), (1999) Culturas ganaderas de Castilla y León. Alberche, Corneja, Sayago y Serrezuela. Instituto de Investigaciones Antropológicas de Castilla y León, Salamanca.

CARO BAROJA, J., Realidad y fantasía en el mundo criminal, CSIC (Madrid, 1986).

Terror y terrorismo, Plaza y Janés (Barcelona, 1989)

GAUTHIER, TH., Viaje a España, Cátedra, Madrid, 1989).

GONZÁlEZ ALCANTUD, J.A., (1999) "Hipótesis etnográficas sobre el bandolerismo monfi", Mélanges. María Soledad Carrasco Urgoiti, Fondation Temimi, Zaghouan.

HERNANDEZ, J., (2000) Martín Fierro, Editorial Plus Ultra, B. Aires.

HOBSBAWM, E.J., (1976) Bandidos, Ariel, Barcelona.

HUMBOLDT, A., (1956) Viaje a las regiones equinocciales del Nuevo Continente, Ediciones del Ministerio de Educación, Caracas.

LÓPEZ ALBÚJAR, E., (1936) Los caballeros del delito, Juan Mejía Baca, Lima
MEDINA MIRANDA, H.M., (2009) Los charros en España y México. Estereotipos ganaderos y violencia lúdica, Tesis Doctoral s.p., Salamanca.

PÁEZ, J.A., (1946) Autobiografía, Librería y Editorial del Maestro, Caracas.

PASTOR Y PETIT, D., (1979) El bandolerismo en España, Plaza y Janet, Barcelona.

RAGO, V., (1999) "Llano y llanero: contribución al estudio del forjamiento de una imagen", Boletín Antropológico, $n^{\circ}$ 45, 27-47.

ROMERO, M.E. (comp.), (1992) Café, caballo y hamaca. Visión histórica del Llano, Eds. Abya-Yala, Quito.

ROMERO HERNÁNDEZ, D.E., (1997) "Enemistades rancheras, bandolerismo y procesos de modernización", Estudios Jaliscienses, n²7,47-67.

ROMERO DE SOLIS, J.M., (1997) "Robar caballos y cometer incesto: el caso de Diego Jerónimo Flores", Estudios Jaliscienses, $n^{\circ} 27,23-35$.

SANCHEZ, G., y MEERTENS, D., (2000) Bandoleros, gamonales y campesinos. El caso de la Violencia en Colombia, El Áncora Editores, Bogotá.

USLAR-PRIETRI, A., (1983) Las lanzas coloradas, Alianza, Madrid.

VV.AA., (2000) "La Charrería", Artes de México, $n^{\circ} 50,6-81$ 